\title{
WORK STRESS-RELATED PROBLEMS IN PHYSICIANS IN THE TIME OF COVID-19
}

\section{FRANCIS SOMVILLE ${ }^{1,2}$, GERT VANSPRINGEL ${ }^{3}$, HARALD DE CAUWER ${ }^{4,5}$, ERIK FRANCK $^{6}$, and PETER VAN BOGAERT ${ }^{6}$}

${ }^{1}$ University of Antwerp, Wilrijk, Belgium

University Hospital Antwerp, Department of Emergency Medicine

${ }^{2}$ Algemeen Ziekenhuis Sint Dimpna, Geel, Belgium

Department of Emergency Medicine

${ }^{3}$ Algemeen Ziekenhuis Sint-Jozef, Malle, Belgium

Department of Emergency Medicine

${ }^{4}$ Algemeen Ziekenhuis Sint Dimpna, Geel, Belgium

Department of Neurology

${ }^{5}$ University of Antwerp, Wilrijk, Belgium

Department of Medicine and Health Sciences

${ }^{6}$ University of Antwerp, Wilrijk, Belgium

Department of Nursing and Midwifery Sciences, Centre for Research and Innovation in Care (CRIC)

\begin{abstract}
Objectives: Healthcare workers in the emergency department are exposed to a wide range of physical and psycho-social risks or hazards in the workplace. The aim of this study was to investigate the impact of exposure to, the occurrence and perceived risks of, and the worry about, occupational hazards among emergency and hospital physicians in the time of COVID. Material and Methods: Based on the review of occupational hazards in emergency physicians, a questionnaire already used and validated in another study, conducted in 2016, was constructed. The questionnaire consisted of both socio-demographic questions and questions regarding the exposure to, the occurrence and perceived risks of, and the worry about, the following occupational hazards: infectious diseases, COVID-19, physical hazards, violence at work, and stressful situations at work that can cause burnout. A total of 497 questionnaires were distributed to Belgian emergency and hospital physicians in April 20-May 26, 2020. Results: Overall, 319 responses (out of 497 questionnaires) were collected, of which 196 were eligible for statistical analysis. Of the respondents, $32 \%$ stated to be confronted with violence and 54\% to suffer from health problems related to their work. The exposure to, and the occurrence and perceived risks of, occupational hazards and, more specifically, the exposure to COVID-19 (88\%) and its occurrence (10\%), and also the worry about these hazards, appear to be high in physicians working in the emergency department. The worry about each of these outcomes is predicted by the supposed exposure, occurrence, and perceived risks. Conclusions: The exposure to, and the occurrence and perceived risks of, physical hazards, violence and burnout are generally high in physicians in the time of COVID-19. Emergency and hospital physicians in Belgium worry the most about the impact of violence, burnout and COVID-19. Int J Occup Med Environ Health. 2021;34(3):373-83
\end{abstract}

Key words:

stress, physicians, physical hazards, psychological hazards, occupational hazards, COVID-19

Received: June 4, 2020. Accepted: October 15, 2020.

Corresponding author: Francis Somville, Algemeen Ziekenhuis Sint Dimpna, Department of Emergency Medicine, J.B. Stessenstraat 2, 2440 Geel, Belgium (e-mail: secretariaatsom@hotmail.com). 


\section{INTRODUCTION}

In November 2019, a novel coronavirus disease COVID-19, emerged in Wuhan, the capital city of the Hubei Province of China [1]. The disease spread within a few months throughout China and elsewhere, becoming a global health concern [2]. In early March, its transmission within Belgium was confirmed and the pandemic rapidly evolved, with its peak of infections in Belgium around the beginning of April 2020 resulting in 1661 new infections in 1 day. Because of the nature of their work, healthcare workers are exposed to a wide range of physical and psycho-social risks or hazards in the workplace [3].

Moreover, since medical and nursing staff are on the frontline of any epidemic, research on the healthcare workers' mental well-being during earlier viral outbreaks, such as the 2003 SARS outbreak, has indicated that the impact on the medical staff members' mental health is significant [4].

Although all healthcare workers are exposed to some risk of infection during a respiratory illness outbreak, some specialties are likely to be at higher risk than others. Emergency physicians and critical care staff are likely to be at higher risk than those in unrelated or non-acute specialties [5]. The combination of working completely dressed up for preventing the infection, working in high-risk positions, the continuously increasing number of confirmed and suspected cases, the depletion of personal protection equipment, the overwhelming workload, having contact with infected people, as well as the fact that healthcare workers risk their own lives in the line of duty, may all contribute to the mental strain resulting in huge stress reactions with possible shortand longer-term psychological consequences [6,7].

Also, emergency healthcare staff members reported occasional exposures to bloodborne pathogens [8] hepatitis B, hepatitis $\mathrm{C}$, non- $\mathrm{A}$, non-B hepatitis, human immunodeficiency virus (HIV) [9], Mycobacterium tuberculosis, latex allergy, nitrous oxide, and COVID-19, but also verbal aggression and physical violence during the COVID-19 outbreak [8-11], and psychological symptoms related to stressful situations at work [12,13]. During the SARS 2003 outbreak, 1 in 5 cases were healthcare staff [14], and recent data from Italy have indicated that almost $20 \%$ of healthcare workers were infected with COVID-19 [15]. Also, there is evidence that physical factors are one of the major sources of worry among emergency and hospital physicians, especially during epidemic outbreaks, leading to some form of emotional turmoil such as burnout or depression [16]. Work-related stress is, moreover, a well-defined problem in healthcare workers [17-20], and especially among emergency care professionals who are confronted not only with a constantly varying, hectic and irregular work environment but also with traumatic incidents, with injured persons and choices about life and death [21]. Consequently, the aim of this study was to investigate the impact of:

- the exposure to, and the occurrence and perceived risks of, the occupational hazards among emergency and hospital physicians in the time of COVID-19,

- the determinants of worry about the occupational hazards among emergency and hospital physicians in the time of COVID-19.

The authors have hypothesized that working on the frontline during the COVID-19 pandemic involves more worrying and severe mental sequels in relation to the exposure to, and the occurrence and perceived risks of, infectious diseases among emergency and hospital physicians. Furthermore, a positive relationship between the determinants of worry about infectious diseases, violence, burnout and COVID-19, and these occupational hazards, has been hypothesized.

\section{MATERIAL AND METHODS \\ Ethics}

The ethical approval from the local Bioethics Committee of AZ Sint Dimpna Geel (EC No. OG 099, bioethical approval No. 709, conforming to the Helsinki Declaration as 
revised in 2013) was obtained for this study. Confidentiality was guaranteed to all the participants. Informed consent was signed by each respondent before data collection.

\section{Study data and participants}

Data was obtained from emergency and hospital physicians using a questionnaire, based on a review of occupational hazards in physicians [10,21]. The study participants were recruited via social media (April 20-May 26, 2020). The questionnaire was also distributed via social media, using a specific survey link, to the participants (in April-May 2020). It was sent to 497 physicians in 8 weeks of the lockdown, which in Belgium already started on March 13, 2020. Of these, 319 signed the informed consent form and returned the questionnaire, which resulted in 196 eligible questionnaires.

\section{Survey configuration}

The survey consisted of questions related to demographic (age, gender) and professional characteristics (seniority, occupation), as well as questions on the exposure to, the occurrence and perceived risks of, and the worry about, occupational hazards [10,21].

In connection with the above purpose, hazards were explored for the following 4 categories:

- infectious diseases (bloodborne pathogens, hepatitis B, hepatitis C, non-A, non-B hepatitis, COVID-19, HIV, and Mycobacterium tuberculosis);

- other physical hazards (latex allergy, radiation exposure, and nitrous oxide);

- violence at work (verbal and non-verbal);

- burnout (based on the Utrecht Burnout Scale) due to work-related stress factors .

For each of these hazards, (or "clusters and hazards" items), the following questions were asked:

- Exposure: Have you ever been, in your function as a physician, exposed to one of the following infections/ work-related problems? Yes/No (scale: 1-0);
- Occurrence: Have you ever, in your function as a physician, experienced one of the following infections/workrelated problems? Yes/No (scale: $1-0$ );

- Risk perception: To what extent do you estimate the risk of contracting (getting) one of the following infections/work-related problems? (a 10-pt Likert scale, from 1 - no risk to 10 - extremely high risk);

- Worry: To what extent do you worry about contracting (getting) one of the following infections/work-related problems? (a 5-pt Likert scale: 1 - never, 2 - rarely, 3 -sometimes, 4 - most of the time, or 5 - almost always).

\section{Statistical data analysis}

The statistical software package for Windows, SPSS v. 26.0, was used to analyze the data. Descriptive statistics (means, standard deviations, percentages) were computed. Pearson's correlations were calculated between all possible predictors and outcomes. Hierarchical regression analyses were performed to estimate the strength of the association between the predictors' demographic characteristics (block 1); the exposure to, and the occurrence of, physical (infectious) hazards, COVID-19, violence, work-related stress factors that can cause burnout symptoms/the occurrence of burnout symptoms (block 2), and perceived risks due to these hazards (block 3), on the one hand, and the outcome variables regarding the worry about physical (infectious) hazards, COVID-19, violence, burnout symptoms due to work-related stress factors, on the other hand.

\section{RESULTS}

\section{Physicians' characteristics}

More than half of the emergency and hospital physicians surveyed were male $(54 \%)$, and $51 \%$ of the respondents were aged $<40$ years. In addition, $42 \%$ of the physicians were emergency physicians. The average number of years the respondents worked in the emergency department was 7 years (SD 6.8); $85 \%$ of them worked full-time in the hospital, and $66 \%$ worked in a rotating shift work schedule. 
Table 1. The exposure to, the occurrence and perceived risks of, and the worry about, occupational hazards in emergency and hospital physicians ( $\mathrm{N}=196)$ in Belgium (April 20-May 26, 2020)

\begin{tabular}{lcccc}
\hline \multirow{2}{*}{ Variable } & \multicolumn{3}{c}{ Questions about occupational hazards } \\
\cline { 2 - 4 } & $\begin{array}{c}\text { exposure } \\
{[\mathrm{n}(\%)]}\end{array}$ & $\begin{array}{c}\text { occurrence } \\
{[\mathrm{n}(\%)]}\end{array}$ & $\begin{array}{c}\text { risk } \\
(\mathrm{M} \pm \mathrm{SD})\end{array}$ & $\begin{array}{c}\text { worry } \\
(\mathrm{M} \pm \mathrm{SD})\end{array}$ \\
\hline Infectious diseases (physical hazards) & & & & \\
$\quad$ bloodborne pathogens & $98(50)$ & $5(3)$ & $3.58 \pm 2.56$ & $1.99 \pm 1.16$ \\
hepatitis B & $138(70)$ & $5(3)$ & $3.08 \pm 2.50$ & $1.76 \pm 1.09$ \\
hepatitis C & $131(67)$ & $3(2)$ & $3.52 \pm 2.27$ & $2.02 \pm 1.13$ \\
non-A, non-B hepatitis & $89(45)$ & $3(2)$ & $3.31 \pm 2.35$ & $1.92 \pm 1.16$ \\
COVID-19 & $172(88)$ & $20(10)$ & $6.08 \pm 2.50$ & $3.17 \pm 1.24$ \\
HIV & $142(73)$ & $4(2)$ & $3.21 \pm 2.36$ & $2.17 \pm 1.22$ \\
Mycobacterium tuberculosis & $140(72)$ & $11(6)$ & $3.67 \pm 2.38$ & $2.19 \pm 1.20$ \\
Non-infectious factors (physical hazards) & & & & \\
latex allergy & $79(41)$ & $11(6)$ & $3.20 \pm 2.69$ & $1.72 \pm 1.08$ \\
radiation & $106(54)$ & $25(13)$ & $3.70 \pm 2.79$ & $2.06 \pm 1.25$ \\
nitrous oxide inhalation & $81(42)$ & $22(11)$ & $3.68 \pm 2.57$ & $1.92 \pm 1.21$ \\
Violence & $126(65)$ & $63(32)$ & $5.73 \pm 2.94$ & $2.59 \pm 1.35$ \\
Burnout (due to work-related stress factors) & $80(41)$ & $47(24)$ & $5.55 \pm 2.63$ & $2.80 \pm 1.23$ \\
\hline
\end{tabular}

HIV - human immunodeficiency virus.

Exposure: yes - I have been exposed to the hazard (yes/no; scale: 1-0); occurrence: yes - I have personally experienced the hazard (yes/no; scale: 1-0); risk perception: a 10-pt Likert scale (from 1 - no risk to 10 - extremely high risk); worry: a 5-pt Likert scale (1- never, 2 - rarely, 3 - sometimes, 4 - most of the time, 5 - almost always).

Table 1 displays the exposure to, the occurrence and perceived risks of, and the worry about, physical hazards (infectious diseases) including COVID-19, physical (non-infectious) hazards, violence and burnout in the emergency and hospital physicians surveyed $(\mathrm{N}=196)$. Two-thirds of the respondents stated to be exposed to infectious diseases, and four-fifths reported being exposed to COVID-19, almost half to non-infectious diseases, $65 \%$ to violence, and $41 \%$ to situations that can cause burnout. The reported rate of occurrence of infectious diseases (bloodborne pathogens, hepatitis $B$, hepatitis $C$, non-A, non-B hepatitis, or HIV) was low compared to the rate of occurrence of other physical hazards (Mycobacterium tuberculosis, latex allergy, radiation, nitrous oxide, or COVID-19). About one-third of the respondents reported the occurrence of violence and one-fourth reported the occurrence of burnout symptoms. The risk for physical (infectious) hazards was seen as much lower than the risk to be confronted with violence, or the risk to develop burnout because of stressful situations at work. However, the risk of getting COVID-19 was 7-10. A similar trend was seen for the worry about all occupational hazards, especially COVID-19.

Table 2 displays the correlations between the predictors and outcomes included in this study, which were reported by the emergency and hospital physicians $(\mathrm{N}=196)$, concerning:

- age;

- working as an emergency physician;

- the exposure to infectious diseases, COVID-19, violence, and burnout; 


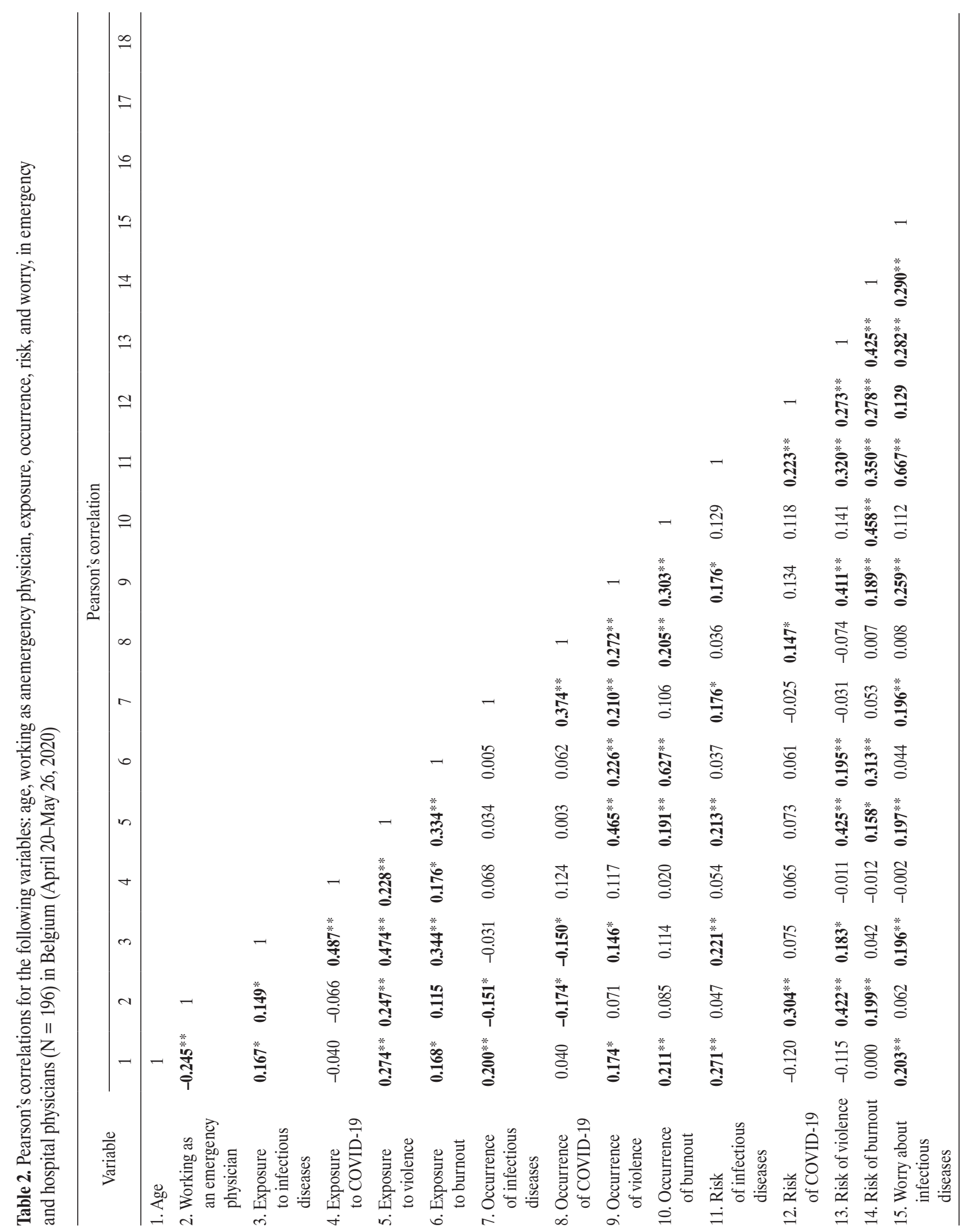


- the occurrence of infectious diseases, COVID-19, violence, and burnout;

- the risk of infectious diseases, COVID-19, violence, and burnout;

- the worry about infectious diseases, COVID-19, violence, and burnout.

Strong correlations were observed between the perceived risks of violence, burnout, and COVID-19, and the worry about violence, burnout, and specifically COVID-19.

\section{Regression analyses}

The results of the hierarchical regression analyses are reported in Table 3.

1. The worry about physical hazards (infectious diseases). The regression model including the personal characteristics such as age, gender, and occupation (block 1) explained $8 \%$ of the variance in the worry about physical hazards. The exposure to, and the occurrence of, physical hazards (block 2) explained an additional $5 \%$ of the variance. The perceived risks (block 3 ) explained an extra $33 \%$ of the variance. All these predictors were significantly related to the outcome. The final model explained $46 \%$ (adjusted $44 \%$ ) of the variance in the worry about physical hazards.

2. The worry about violence. The personal characteristics such as age, gender, and occupation (block 1) explained $11 \%$ of the variance in the worry about violence. The exposure to, and the occurrence of, workrelated violence (block 2) explained $10 \%$ of the variance. The perceived risks (block 3 ) explained an extra $31 \%$ of the variance in the worry about violence. All these predictors were significantly related to the outcome The final model explained 52\% (adjusted 51\%) of the variance in the worry about violence.

3. The worry about burnout. The personal characteristics such as age, gender, and occupation (block 1) explained $2 \%$ of the variance in the worry about burnout. The exposure to, and the occurrence of, burnout 


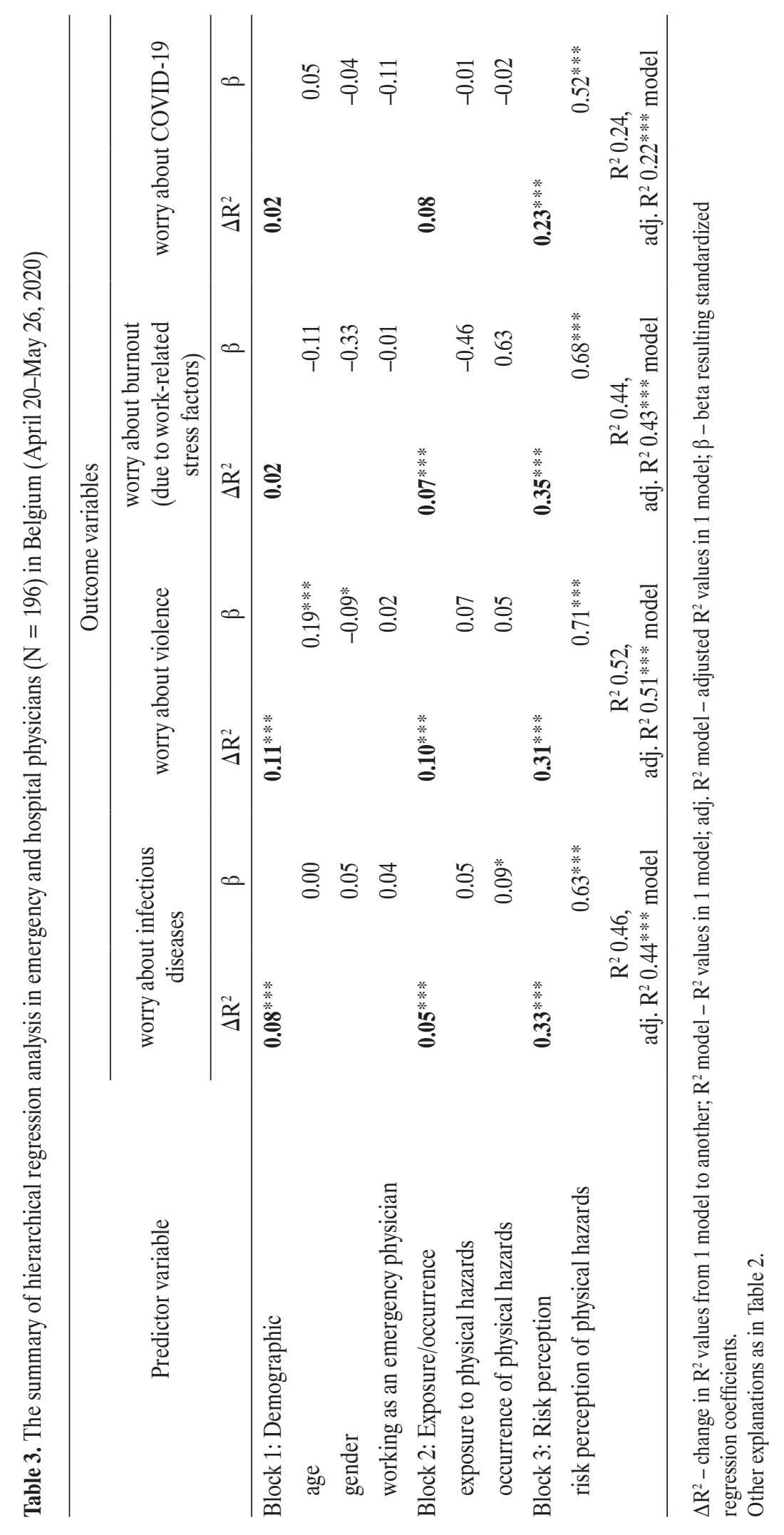


(block 2) explained an additional $7 \%$ of the variance. Both the burnout predictors were significantly related to the outcome. The perceived risks (block 3) explained an extra $35 \%$ of the variance in the worry about burnout. This predictor was significantly related to the outcome. The final model explained 44\% (adjusted 43\%) of the variance in the worry about burnout.

4. The worry about COVID-19. The personal characteristics such as age, gender, and occupation (block 1) explained $2 \%$ of the variance in the worry about COVID-19. The exposure to, and the occurrence of, burnout (block 2) explained an additional $8 \%$ of the variance. Both the COVID-19 predictors were not significantly related to the outcome. The perceived risks (block 3) explained an extra $23 \%$ of the variance in the worry about COVID-19. This predictor was significantly related to the outcome. The final model explained $24 \%$ (adjusted $22 \%$ ) of the variance in the worry about COVID-19.

\section{DISCUSSION}

The purpose of this study was to examine the exposure to, the occurrence and perceived risks of, and the worry about, occupational hazards (physical hazards, violence and work-related stressors that can cause burnout in emergency and hospital physicians, as well as the impact of the perceived exposure, the occurrence and risk perception on the worry about these hazards) during the COVID-19 outbreak in Belgium.

The perceived exposure rate to infectious diseases ranged 45-73\%, which was similar to other studies that showed more variance in exposure rates, between 31-80\% $[1,2,5,10]$. In this study, the perceived exposure rate to COVID-19 was even higher (88\%).

Earlier studies reported the occurrence of infectious diseases at $1-3 \%$ which is comparable to these findings concerning the occurrence of bloodborne pathogens, hepatitis $\mathrm{B}$, hepatitis $\mathrm{C}$, non-A, non-B hepatitis, and HIV (2-3\%), and Mycobacterium tuberculosis (6\%), but they were in contrast to these findings as regards the higher occurrence of COVID-19 (10\%) in the sample involved in this study. The perceived exposure to non-infectious hazards for latex allergy, radiation, and nitrous oxide inhalation ranged $41-54 \%$. As in previous studies, the perceived exposure was higher in the physicians working in the emergency department [10,22-24].

The occurrence of non-infectious hazards in previous studies varied between 6-17\%. In this study, an occurrence of $6 \%$ was reported for latex allergy, which could be moderately compared to the Canadian study (10\%) [22]. An occurrence of $13 \%$ of radiation was found in this study, which was higher in comparison to the U.S. study (10\%) [23]. The occurrence of nitrous oxide inhalation described in this study $(11 \%)$ was also $<25 \%$ reported in the U.S. study [24].

The perceived risk perception reported by the emergency and hospital physicians involved in this study varied from a lower $3.20(\mathrm{SD}=2.69)$ for latex allergy to a moderate $3.68(\mathrm{SD}=2.57)$ for nitrous oxide inhalation.

The emergency and hospital physicians involved in this study reported a high perceived exposure to violence during the COVID-19 outbreak. This is not surprising since the physicians working in the emergency department are frequently confronted with violent patients such as intoxicated people, wrongdoers, committers of violence and their victims $[3,10,17]$. The reported occurrence of violence in this study was $32 \%$, similar to other studies [17]. The perceived risk of violence was much higher than for physical hazards, which was also comparable to other studies $[15,16,25]$. However, the perceived risk of COVID-19 was much higher during the lockdown period.

For stressful situations at work that can cause burnout, the authors observed a high rate of the perceived exposure in almost two-fifths of the emergency and hospital physicians (41\%). The perceived exposure to situations that can cause burnout was similarly high in other studies in non-COVID-19 times [26]. Overall, 24\% of the emer- 
gency and hospital physicians reported the occurrence of burnout symptoms in this study, as in other studies [11,27]. The perceived risk of burnout was high, although lower than the perceived risk of violence. This was also observed in another study [28]. The authors further observed that the perceived risk of COVID-19 was also higher than the other risks.

This study has indicated that physical hazards, and especially violence and burnout, are prevalent in physicians. The worry about physical hazards, violence, and burnout may lead to adverse consequences in terms of the quality of care, lifestyle, and job satisfaction [27,29]. The worry about COVID-19 was found in two-thirds of the respondents and could have probably lead to an adverse attitude towards the way of coping with these consequences. The high worry about violence indicated that the physicians working in the emergency department were concerned about the verbal and physical consequences of violence, as was also described by other authors [17,29]. The high levels of the worry about burnout, as revealed in this study, were also found in other studies in physicians [26,30]. The very high worry about COVID-19 shows that one has to be concerned for the physicians working in the workplace where such a worry and perceived risks are present, and this is not to be neglected in an area where potential contamination is present, with the emergency department being one of these.

\section{Strengths and limitations}

The majority of the physicians who participated in the study were working in large non-academic emergency care departments. This could be a source of bias because exposure to occupational hazards may be different in academic hospitals. Besides, this was a cross-sectional study. A longitudinal study could investigate the stability of these findings. Finally, all the participants were recruited via social media during the lockdown period. This may have led to a rather conservative estimate of both the occupational hazards and the impact of COVID-19.
The participants could have little influence on the answers of other physicians who completed the questionnaire. The fact that so many physicians working in the field reported the same problems and hazards proves that this is indeed an important problem.

\section{CONCLUSIONS}

The exposure to, and the occurrence and perceived risks of, physical hazards, and even more violence, burnout, and especially COVID-19, are high in the physicians working in the emergency department. These occupational hazards indeed constitute a substantial worry for the physicians in the time of COVID-19. Further studies about the consequences of worry in this group of physicians are important to explore the relationship with job demands, job control, satisfaction, absenteeism, work turnover, and physical and psychological health.

\section{ACKNOWLEDGMENTS}

The authors would like to thank the physicians who anonymously participated in the survey and wish to thank them for their participation in this questionnaire study. The authors would also like to thank Junior Resident K. Vervaeke for his technical help.

\section{REFERENCES}

1. Chan J, Yuan S, Kok KH, To KK, Chu H, Yang J, et al. A familial cluster of pneumonia associated with the 2019 novel coronavirus indicating person-to-person transmission: a study of a family cluster. Lancet 2020;395(10223):514-23, https:// doi.org/10.1016/S0140-6736(20)30154-9.

2. World Health Organization [Internet]. Geneva: The Organization; 2020 [cited 2020 Feb 15]. Statement on the second meeting of the International Health Regulations (2005) Emergency Committee regarding the outbreak of novel coronavirus (2019-nCoV). Available from: https://www.who.int/news/ item/30-01-2020-statement-on-the-second-meeting-of-the-international-health-regulations-(2005)-emergency-committeeregarding-the-outbreak-of-novel-coronavirus-(2019-ncov). 
3. Udasin IG. Health care workers. Prim Care. 2000;27(4): 1079-102, https://doi.org/10.1016/s0095-4543(05)70190-1.

4. Maunder R, Lancee WJ, Balderson KE, Bennett JP, Borgundvaag B, Evans S, et al. Long-term psychological and occupational effects of providing hospital healthcare during SARS outbreak. Emerg Infect Diseas. 2006;12(12):1924-32, https://doi.org/10.3201/eid1212.060584.

5. Simonds A, Sokol D. Lives on the Line? Ethics and Practicalities of Duty of Care in Pandemics and Disasters. Eur Respir J. 2009;34(2):303-9, https://doi.org/10.1183/0903193 6.00041609 .

6. Khalid I, Khalid T, Qabajah M, Barnard A, Qushmaq I. Healthcare Workers Emotions, Perceived Stressors and Coping Strategies During a MERS-CoV Outbreak. Clin Med Res. 2016;14(1):7-14, https://doi.org/10.3121/cmr.2016.1303.

7. Lai J, Ma S, Wang Y, Cai Z, Hu J, Wei N, et al. Factors Associated With Mental Health Outcomes Among Health Care Workers Exposed to Coronavirus Disease 2019. JAMA Netw Open. 2020;3(3):e203976, https://doi.org/10.1001/jama networkopen.2020.3976.

8. Udasin IG, Gochfeld M. Implications of the Occupational Safety and Health Administration's bloodborne J Occup Med. 1994;36(5):548-55.

9. Calfee DP. Prevention and management of occupational exposures to human immunodeficiency virus (HIV). Mt Sinai J Med. 2006;73(6):852-6.

10. Dorevitch S, Frost L. The occupational Hazards of Emergency Physicians. Am J Emerg Med. 2000;18(3):300-11, https://doi.org/10.1016/s0735-6757(00)90125-6.

11. Estryn-Behar M, Doppia MA, Guetami K. Emergency Physicians accumulate more stress than other physicians - results from the SESMAT study. Emerg Med J. 2011;28(5):397410, https://doi.org/10.1136/emj.2009.082594.

12. Hart P, Cooper C. Occupational stress: toward a more integrated framework. In: Anderson N, Ones DS, Sinangil HK, Viswesvaran C, editors. Handbook of Industrial, Work and Organizational Psychology. Vol. 2. Personnel Psychology. London: Sage; 2001. p. 93-114.
13. Potter $\mathrm{C}$. To what extent do nurses and physicians working within the emergency department experience burnout: a review of the literature. Australas Emerg Nurs J. 2006;9(2):57-64.

14. Chan-Yeung M. Severe Acute Respiratory Syndrome (SARS) and Healthcare Workers. Int J Occup Environ Health. 2004;10(4):421-7, https://doi.org/10.1179/oeh.2004.10.4.421.

15. Remuzzi A, Remuzzi G. COVID-19 and Italy: What Next? Lancet. 2020;395(10231):1225-8, https://doi.org/10.1016/S01 40-6736(20)30627-9.

16. Liao Q, Cowling B, Lam W, Ng D, Fielding R. Anxiety, Worry and Cognitive Risk Estimate in Relation to Protective Behaviors During the 2009 Influenza A/H1N1 Pandemic in Hong Kong: Ten Cross-Sectional Surveys. BMC Infect Dis. 2014;14:169, https://doi.org/10.1186/1471-2334-14-169.

17. Gates DM, Ross CS, McQueen L. Violence against emergency department workers. J Emerg Med. 2006;31(3):331-7, https://doi.org/10.1016/j.jemermed.2005.12.028.

18. Fernandes C, Bouthillette F, Raboud J, Bullock L, Moore C, Christenson J, et al. Violence in the emergency department: a survey of health care workers. CMAJ. 1999;161(10): $1245-8$.

19. Kowalenko T, Walters BL, Khare RK, Compton S. Michigan College of Emergency Physicians Workplace Violence Task Force: Workplace violence: a survey of emergency physicians in the state of Michigan. Ann Emerg. Med. 2005;46(2): 142-7, https://doi.org/10.1016/j.annemergmed.2004.10.010.

20. Burbeck R, Coomber S, Robinson SM, Todd C. Occupational stress in consultants in accident and emergency medicine: a national survey of levels of stress at work. Emerg Med J.2002;19(3):234-8, https://doi.org/10.1136/emj.19.3.234.

21. Somville FJ, De Gucht V, Maes S. The Impact of Occupational Hazards and Traumatic Events among Belgian Emergency Physicians. Scand J Trauma Resusc Emerg Med. 2016; 24:59, https://doi.org/10.1186/s13049-016-0249-9.

22. Arellano R, Bradley J, Sussman G. Prevalence of latex sensitization among hospital physicians occupationally exposed to latex gloves. Anesthesiology. 1992;77:905-8, https://doi. org/10.1097/00000542-199211000-00011. 
23. Weiss EL, Singer CM, Benedict SH, Baraff LJ. Physician exposure to ionizing radiation during trauma resuscitation: a prospective clinical study. Ann Emerg Med. 1990;19:134-8, https://doi.org/10.1016/s0196-0644(05)81797-4.

24. Dula DJ, Skiendzielewski JJ, Royko M. Nitrous oxide levels in the emergency department. Ann Emerg Med. 1981;10: 575-8, https://doi.org/10.1016/s0196-0644(81)80195-3.

25. Kansagra SM, Sowmya RR, Sullivan AF. A survey of workplace violence across 65 U.S. emergency departments. Acad Emerg Med. 2008;15:1268-74, https://doi.org/10.1111/j.15532712.2008.00282.x.

26. Gallery ME, Whitley TW, Klonis LK, Anzinger RK, Revicki DA. A study of occupational stress and depression among emergency physicians. Ann Emerg Med. 1992;21(1): 58-64, https://doi.org/10.1016/s0196-0644(05)82238-3.

27. Goldberg R, Boss RW, Chan L, Goldberg J, Mallon WK, Moradzadeh $\mathrm{D}$, et al. Burnout and its correlates in emergency physicians: Four years' experience at a wellness both. Acad Emerg Med. 1996;3:1156-64, https://doi.org/10.1111/j.15532712.1996.tb03379.x.

28. Maslach C, Jackson S. Burnout in Health Professions A Social Psychological Analysis. In: Sanders GS, Suls J, editors. Social Psychology of Health and Illness. Hillsdale: Erlbaum; 1982. p. 227-51.

29. Gregov L, Kovačević A, Slišković A. Stress among Croatian physicians: comparison between physicians working in emergency medical service and health centers - pilot study. Croat Med J. 2011;52(1):8-15, https://doi.org/10.3325/cmj. 2011.52.8.

30. Crook HD, Taylor DM. Workplace factors leading to planned reduction of clinical work among emergency physicians. Emerg Med Australas. 2004;16(1):28-34, https://doi.org/10. 1111/j.1742-6723.2004.00531.x.

This work is available in Open Access model and licensed under a Creative Commons Attribution-NonCommercial 3.0 Poland License - http://creativecommons.org/ licenses/by-nc/3.0/pl/deed.en. 